\title{
Epidemiology of Clostridium difficile infection in hospitalized adults and the first isolation of $C$. difficile PCR ribotype 027 in central China
}

Yu Zhou ${ }^{1+}$, Liyan $\mathrm{Mao}^{2 \dagger}$, Jing Yu², Qun Lin², Ying Luo ${ }^{2}$, Xuhui Zhu ${ }^{2^{*}}$ and Ziyong Sun ${ }^{2^{*}}$

\begin{abstract}
Background: Clostridium difficile infection (CDI) is an emerging healthcare problem in the world. The purpose of this study was to perform a systematic epidemiological research of CDI in Tongji hospital, the central of China.

Methods: Stool samples from hospitalized adults suspected of CDI were enrolled. The diagnosis of CDI were based on the combination of clinical symptoms and laboratory results. Clinical features of CDI and non-CDI patients were compared by appropriate statistical tests to determine the risk factors of CDI. Multilocus sequence typing (MLST) was employed for molecular epidemiological analysis. Susceptibility testing and relevant antimicrobial agent resistance genes were performed as well.
\end{abstract}

Results: From June 2016 to September 2017, 839 hospitalized adults were enrolled. Among them, 107 (12.8\%, 107/ 839) patients were $C$. difficile culture positive, and $73(8.7 \%, 73 / 839)$ were infected with toxigenic $C$. difficile (TCD), with $t c d A+t c d B+$ strains accounting for $90.4 \%$ (66/73) and $t c d A-t c d B+$ for 9.6\% (7/73). Meanwhile, two TCD strains were binary toxin positive and one of them was finally identified as CD027. Severe symptoms were observed in these two cases. Multivariate analysis indicated antibiotic exposure $(p=0.001, \mathrm{OR}=5.035)$ and kidney disease $(p=0$. 015, $O R=8.329)$ significantly increased the risk of CDI. Phylogenetic tree analysis demonstrated 21 different STs, including one new ST (ST467); and the most dominant type was ST54 (35.6\%, 26/73). Multidrug-resistant (MDR) TCD were 53.4\% (39/73); resistance to ciprofloxacin, erythromycin, and clindamycin were $>50 \%$. Other antibiotics showed relative efficiency and all strains were susceptible to metronidazole and vancomycin. All moxifloxacinresistant isolates carried a mutation in GyrA (Thr82 $\rightarrow \| l$ ), with one both having mutation in GyrB (Ser366 $\rightarrow$ Ala).

Conclusions: Knowledge of epidemiological information for CDI is limited in China. Our finding indicated $t c d A+t c d B+$ C. difficile strains were the dominant for CDI in our hospital. Significant risk factors for CDI in our setting appeared to be antibiotic exposure and kidney disease. Metronidazole and vancomycin were still effective for CDI. Although no outbreak was observed, the first isolation of CD027 in center China implied the potential spread of this hypervirulent clone. Further studies are needed to enhance our understanding of the epidemiology of CDI in China.

Keywords: Clostridium difficile infection, Clostridium difficile ribotype 027, Risk factor, Molecular characterization, Drug resistance

\footnotetext{
*Correspondence: zhuxuhui2002@163.com; zysun@tjh.tjmu.edu.cn

${ }^{\dagger}$ Yu Zhou and Liyan Mao contributed equally to this work.

${ }^{2}$ Department of Laboratory Medicine, Tongji Hospital, Tongji Medical College,

Huazhong University of Science and Technology, No. 1095 Jiefang Road,

Wuhan 430030, China

Full list of author information is available at the end of the article
}

(c) The Author(s). 2019 Open Access This article is distributed under the terms of the Creative Commons Attribution 4.0 International License (http://creativecommons.org/licenses/by/4.0/), which permits unrestricted use, distribution, and reproduction in any medium, provided you give appropriate credit to the original author(s) and the source, provide a link to the Creative Commons license, and indicate if changes were made. The Creative Commons Public Domain Dedication waiver (http://creativecommons.org/publicdomain/zero/1.0/) applies to the data made available in this article, unless otherwise stated. 


\section{Background}

Clostridium difficile infection (CDI), which is caused by toxigenic $C$. difficile (TCD), has been linked to healthcare facility-associated (HCFA) diarrhea since 1977 [1]. The clinical symptoms of CDI vary from asymptomatic carriage to diarrhea or more severe manifestations, such as pseudomembranous colitis, toxic megacolon and even death [2]. Published data suggest a decline in CDI incidence in hospitalized patients after 2009, but the number of cases remains high. An estimated annual incidence of CDI is 453,000 in the United States, 172,000 in Europe, and 18,005 in England [3, 4], while little is known about the prevalence and impact of CDI in China. The widely accepted major risk factors for CDI include old age ( $\geq 65$ years), antibiotic exposure, prolonged length of hospital stay, comorbidities such as chronic kidney disease, inflammatory bowel disease, immunodeficiency and immunosuppression [5]. However, reports on community-acquired (CA) CDI have increased among young people who lack the traditional risk factors [6]. Meanwhile, clinical practice guidelines of the Society for Healthcare Epidemiology of America (SHEA) and the Infectious Diseases Society of America (IDSA) claim leukocytosis and increased serum creatinine levels are able to reflect the severity of CDI [7]. Results of a previous study which analyzed 70 patients (> 80 years) with CDI indicated that higher white blood cell counts were independently associated with treatment failure [8].

First detected in North America, the hypervirulent strain $C$. difficile ribotype 027 (CD027), which produces toxin $\mathrm{A}$, toxin $\mathrm{B}$ and a third unrelated binary toxin (CDT), as well as carrying an $18 \mathrm{bp}$ deletion in $t c d C$ gene, has spread rapidly in various countries in Europe [9]. However, the epidemiology of CDI has changed over the past two decades [10]. Although CD027 remains the dominant clone in the United States, it is rarely reported in Asia. This has occurred simultaneously with an increase in other virulent strains globally. Among them, the toxin A negative and toxin B positive $(t c d A-t c d B+)$ strain, has received wide attention $[11,12]$. An increasing number of reports mention severe infections and outbreaks caused by $t c d A-t c d B+$ strains, with a greater frequency in East Asian countries [13]. Some reports also have shown that $t c d A-t c d B+$ strains have significantly higher rates of resistance to clindamycin and moxifloxacin compared with $t c d A+t c d B+$ strains [14].

CDI is an emerging problem in Asia, nevertheless, data on CDI in China are limited due to poor clinical awareness. Particularly, the epidemiological distribution, specific risk factors and antimicrobial susceptibility patterns for $C$. difficile isolates are not known well [15]. Genotyping, a useful epidemiological tool, has been widely used for the analysis of evolutionary paths and comparisons of lineages on a global context [16]. A study by Eyre et al. [17] estimated an evolutionary rate of 0.74 SNP per year for $C$. difficile and different molecular characteristics of $C$. difficile has been observed worldwide [2]. Therefore, not only the clinical features and the antibiotic resistance patterns, but also the molecular epidemiology of CDI were investigated in the present study.

\section{Methods}

\section{Definitions}

Diarrhea was defined as more than 3 unformed stools within $24 \mathrm{~h}$ (according to Bristol stool chart types 5-7). CDI diagnosis was based on the combination of clinical symptoms and laboratory results, which was defined as the presence of diarrhea and a stool test that was positive for the TCD (Xpert C. difficile assay) or clinical evidence of pseudomembranous colitis [7]. Only the first stool sample was collected from each patient. Adult patients were defined as $\geq 18$ years old. The epidemiological associations of CDI were divided into two types: 1) HCFA, the symptoms developed after $48 \mathrm{~h}$ of admission or within 12 weeks after discharge from a healthcare facility; 2) CA, the symptoms developed before $48 \mathrm{~h}$ of admission and had not been admitted to a healthcare facility in the previous 12 weeks [18]. According to the Public Health Ontario, C. difficile outbreaks in healthcare facilities were defined as follows: areas $\geq 20$ beds experiencing three new HCFA $C$. difficile cases within a 7-day period or five new cases within a 4-week period. For units $<20$ beds, two new cases in a 7-day period or four new cases within a 4-week period [19].

\section{Study design and $C$. difficile isolates}

From June 2016 to September 2017, hospitalized diarrheal adults who were suspected of CDI by physicians in Tongji hospital (the largest teaching hospital in central China, which treats patients from the six surrounding provinces [20]) were enrolled. Their stool samples (semi-formed, unformed or liquid) submitted to the clinical microbiology laboratory for $C$. difficile detection were collected. The following clinical data of enrolled patients were recorded: demographic data (including age, gender, HCFA versus CA, and comorbidity), presumed risk factors in the 4 weeks before the onset of diarrhea (including prior hospitalization, antibiotic exposure, proton pump inhibitors, nasogastric intubation, abdominal surgery, chemotherapy and immunosuppressive agents treatment), biological parameters (including white blood cell count [WBC], percentage of neutrophile granulocyte [NEU\%], hemoglobin [HB], blood platelet count [PLT], albumin [ALB], glutamic oxalacetic transaminase $[\mathrm{AST}]$, serum creatinine [CRE] and high sensitivity $C$ reactive protein [hsCRP]), and clinical symptoms (including abdominal pain, fever, vomit and 
hematochezia) [1]. Relevant laboratory results, only measured within \pm 3 days of the $C$. difficile detection were recorded. All the collected stool samples were simultaneously subjected to $C$. difficile culture for further study. C. difficile colonies were identified on the basis of their typical morphology (flat, black and ground-glass appearance) on selective ChromID C. difficile agar (bioMérieux, Marcy l'Etoile, France) and were further confirmed by matrix-assisted laser desorption/ ionization time of flight mass spectrometry (MALDI-MS) using the MALDI Biotyper (Bruker Daltonik $\mathrm{GmbH}$, Leipzig, Germany) according to the operating manual [21]. Isolates were stored at $-80^{\circ} \mathrm{C}$ using a Microbank ${ }^{\ominus}$ bacterial reservation system (Pro-Lab Diagnostics, Richmond Hill, ON, Canada). This research was approved by the ethics committee of Tongji Hospital. Informed consents were obtained from patients for the use of samples in our research.

\section{DNA extraction and toxin genes detection}

If testing positive for C.difficile, genomic DNA of C. difficile isolation was extracted from bacterial cultures on blood agar using E.Z.N.A. Stool DNA Kit (Omega Bio-Tek, Norcross, Georgia, USA) according to the manufacturer's instructions. The extracted DNA was amplified for the $16 s \mathrm{rDNA}, t c d A, t c d B, c d t A, c d t B$, and $t c d C$ genes of $C$. difficile in a single multiplex PCR, as described in [22]. For the apparently high isolation rate of $t c d A-t c d B+$ strains in Asia might reflect mismatching of PCR primers as a result of $C$. difficile polymorphisms [23], all TCD strains were simultaneously detected by NK11/NK9 primer set to verify $t c d A$ [24].The standard C. difficile strains (ATCC 43596, ATCC 43598, C. difficile BI/027/NAP1) obtained from the American Type Culture Collection (Manassas, VA, USA) were used as positive controls for $t c d A+t c d B+, t c d A-t c d B+$ and binary toxin genes, respectively. C. difficile ATCC 700057 (Manassas, VA, USA) was chosen as negative controls for $t c d A, t c d B$ and the binary toxin genes.

\section{Multilocus sequence typing (MLST)}

Described by Griffiths et al. [25], MLST was used to analyze the sequence types (STs) of all the TCD strains. PCR was conducted to assess seven housekeeping genes ( $a d k, \operatorname{atp} A, d x r, g l y A, \operatorname{rec} A$, sodA and tpi), and the amplicons were further sequenced using forward and reverse primers. The DNA sequences were submitted to the MLST database (http://pubmlst.org/cdifficile/) to obtain the ST types and clade clusters. Based on the tandem sequence of seven housekeeping genes, phylogenic trees were constructed using the neighbor-joining (NJ) method via MEGA software (version 5.2) (http:// www.megasoftware.net/). Bootstrapping was performed with 1000 replicates [21].

\section{PCR ribotyping}

PCR ribotyping was performed as a supplement for CD027 identification. Primers 16S (5'-GTGCGGCTG GATCACCTCCT-3') and $23 \mathrm{~S}$ (5'-CCCTGCACC CTTAATAAC TTGA CC-3') were used for classic agarose gel-based PCR ribotyping. Details referred to the methods described by Bidet et al. [26]. C. difficile BI/ 027/NAP1 was used as the reference.

\section{Susceptibility testing}

Minimum inhibitory concentrations (MICs) of 14 antimicrobial agents were determined by the agar dilution method as recommended by the Clinical and Laboratory Standards Institute (CLSI) [27]. Results of antibiotic susceptibility were interpreted according to CLSI guidelines [27] or European Committee on Antimicrobial Susceptibility Testing (EUCAST) [28]. For antimicrobial agents with no standard breakpoints available, resistance was considered as follows: rifampicin, $\geq 32 \mu \mathrm{g} / \mathrm{ml}$; fusidic acid, $>0.5 \mu \mathrm{g} / \mathrm{ml}$; and linezolid, $>4 \mu \mathrm{g} / \mathrm{ml}$ [29]. Strains with resistance to at least three antimicrobial classes were defined as multidrug resistant (MDR). B. fragilis ATCC 25285 and C. difficile ATCC 700057 were used as quality control strain for susceptibility testing.

\section{Detection of resistance genes and mutations}

For isolates showing resistance to moxifloxacin (MIC $\geq 8$ $\mu \mathrm{g} / \mathrm{ml})$, PCR amplification and sequencing of the quinolone resistance determining region of GyrA and GyrB were further performed according to the methods reported by Fumie Adachi [30]. Pairwise alignments of DNA sequences were performed using the BLAST server of the National Center for Biotechnology Information.

\section{Statistical analysis}

The results were expressed as medians and quartiles for continuous variables (because most of them were skewed), and as frequencies and percentages for categorical variables. To examine differences of clinical data (including demographic data, presumed risk factors, presumed risk factors, and clinical symptoms) between CDI patients and the non-CDI controls, D-normality test was used for data distribution detection, and Student's $t$-test was used for continuous data if it was normal distribution, Wilcoxon rank-sum test was employed when the data was abnormal distribution. Chi-square $(\chi 2)$ test was used for categorical data, and if the theoretical frequency of the data in the fourfold table is less than 1 , or the total number of cases is less than 40 , Fisher's exact test was employed [10]. Univariate logistic regression analyses were carried out to assess relevant risk factors of CDI. Only statistically different factors were subsequently analyzed in multivariate logistic regression model. False discovery rate (FDR) estimation was used 
for multiple testing correction. $P<0.05$ was considered statistically significant. Because antibiotic exposure involves the use of different antibiotics, subgroup analyses of antibiotic were conducted to explore the prevalence of CDI in different situations. Odds ratios (ORs) with 95\% confidence intervals (95\% CIs) were presented for the logistic regression analyses. SPSS version 18.0 was used for statistical analysis.

\section{Results}

\section{Clinical features}

In total, there were 839 patients suspected of CDI enrolled. In the population studied, males accounted for $70.3 \%(590 / 839)$ and $21.8 \%(183 / 839)$ patients had CA diarrhea. The mean age was 51 (interquartile range: $36-$ 64) years old, with $20.7 \%(174 / 839) \geq 65$ years old. Most patients were admitted in the April-June (41.7\%, 350/ 839 ), followed by July-September (32.2\%, 270/839). $70.4 \%(591 / 839)$ of the patients were from gastroenterology department. Abdominal pain $(7.6 \%, 64 / 839)$ and hematochezia $(7.5 \%, 63 / 839)$ were the most common symptoms accompanied with diarrhea (details shown in Table 1).

\section{Prevalence of $\mathrm{CDI}$ and assessment of risk factors}

Among 839 enrolled patients, 107 (12.8\%, 107/839) patients were $C$. difficile culture positive and 73 (8.7\%, 73/ 839) TCD strains were isolated. There was a good consistency between the Xpert $C$. difficile assay and multi-PCR in our study, and all the $t c d A-t c d B+$ strains were confirmed by two PCR methods. Of the 73 TCD strains, $t c d A+t c d B+$ accounted for $90.4 \%(66 / 73)$ and $t c d A-t c d B+$ for $9.6 \%(7 / 73)$, with no $t c d A+t c d B$ - strains detected. Furthermore, two $t c d A+t c d B+$ isolates were positive for binary toxin genes and one of which having deletions in $t c d C$ genes was finally identified as CD027 according to the result of GeneXpert, MLST and Ribotyping (gel electrophoresis fingerprint shown in the Additional file 1). Clinical data of those patients with and without CDI were available (shown in Table 2). When age stratification was done, the frequencies of CDI occurring in different age groups were 5.0\% (8/159, $18-30$ years old), $13.8 \%$ (11/80, $30-40$ years old), $11.2 \%$ (17/152, 40-50 years old), $6.9 \%$ (19/275, 50-65 years old), and $10.4 \%$ (18/173, $\geq 65$ years old), respectively (Fig. 1). Chi-square test showed no significant difference of CDI incidence between different age groups. Among 73 TCD strains, $31(42.5 \%, 31 / 73)$ were isolated from the gastroenterology department, $9(12.3 \%, 9 / 73)$ from surgery department, with ICU, infections department, cardiovascular medicine department and respiratory medicine department sharing the same isolate number 4 (5.5\%, 4/73) (Fig. 2).
Table 1 Basic information and clinical symptoms of the 839 enrolled patients suspected of CDI

\begin{tabular}{|c|c|}
\hline Characteristic & Number (\%) \\
\hline \multicolumn{2}{|l|}{ Age(years) } \\
\hline $18-30$ & $158(18.9)$ \\
\hline $30-40$ & $80(9.5)$ \\
\hline $40-50$ & $152(18.1)$ \\
\hline $50-65$ & $275(32.8)$ \\
\hline$\geq 65$ & $174(20.7)$ \\
\hline \multicolumn{2}{|l|}{ Onset of diarrhea } \\
\hline HCFA & $656(78.2)$ \\
\hline CA & $183(21.8)$ \\
\hline \multicolumn{2}{|l|}{ Sex } \\
\hline Male & $590(70.3)$ \\
\hline Female & $249(29.7)$ \\
\hline \multicolumn{2}{|l|}{ Season } \\
\hline Spring (January-March) & $114(13.6)$ \\
\hline Summer (April-June) & $350(41.7)$ \\
\hline Autumn (July-September) & $270(32.2)$ \\
\hline Winter (October-December) & $105(12.5)$ \\
\hline \multicolumn{2}{|l|}{ Department } \\
\hline Gastroenterology department & $591(70.4)$ \\
\hline Surgery department & $49(5.8)$ \\
\hline Hematopathology department & $47(5.6)$ \\
\hline Infections department & $23(2.7)$ \\
\hline Organ transplantation department & $21(2.5)$ \\
\hline Comprehensive medical department & $18(2.1)$ \\
\hline ICU & $13(1.6)$ \\
\hline Cardiovascular medicine department & $13(1.6)$ \\
\hline Respiratory medicine department & $13(1.6)$ \\
\hline Other internal medicine department & $51(6.1)$ \\
\hline \multicolumn{2}{|l|}{ Clinical Symptoms } \\
\hline Abdominal pain & $64(7.6)$ \\
\hline Hematochezia & $63(7.5)$ \\
\hline Fever $\left(>37.2^{\circ} \mathrm{C}\right)$ & $40(4.8)$ \\
\hline Vomit & $9(1.1)$ \\
\hline
\end{tabular}

HCFA healthcare facility-associated, CA community-acquired

Univariate analyses between 73 CDI cases and 766 non-CDI controls were conducted, and the results were shown in Table 2 . Kidney disease $(p<0.001)$, antibiotic exposure $(p=0.003)$, NEU\% $(p=0.035)$ and hypoalbuminemia $(p=0.012)$ were the parameters found statistically difference between CDI cases and controls. Interestingly, some parameters, such as age, gastrointestinal disease, and proton pump inhibitors, which were commonly considered as risk factors, were found no significant difference. In the multivariate logistic regression 
Table 2 Risk factors assessment of 73 CDI patients and 766 non-CDI controls

\begin{tabular}{|c|c|c|c|}
\hline Characteristic & TCD infection $(\mathrm{N}=73) \mathrm{n}(\%)$ & Control $(N=766)$ n (\%) & $P$ value $^{a}$ \\
\hline \multicolumn{4}{|l|}{ Demographic data } \\
\hline Age (Median, Interquartile range) & $52(37.3-64.8)$ & $51(38-63)$ & 0.908 \\
\hline Age $\geq 65$ years & $18(25.0)$ & $155(20.2)$ & 0.868 \\
\hline Male sex & $58(79.5)$ & $500(65.3)$ & 0.098 \\
\hline Community-acquired diarrhea & $15(20.5)$ & $168(21.9)$ & 0.980 \\
\hline Gastrointestinal disease & $22(30.1)$ & $217(28.3)$ & 1.042 \\
\hline Hepatobiliary disease & $6(8.2)$ & $65(8.5)$ & 1.026 \\
\hline Cardiovascular disease & $6(8.2)$ & $51(6.7)$ & $0.910^{b}$ \\
\hline Kidney disease & $9(12.3)$ & $13(1.7)$ & $<0.001^{* * *}$ \\
\hline Hemopathy & $4(5.5)$ & $36(4.7)$ & $1.038^{\mathrm{b}}$ \\
\hline Malignancy & $4(5.5)$ & $21(2.7)$ & $0.843^{b}$ \\
\hline Autoimmune disease & $1(1.4)$ & $15(2.0)$ & $1.000^{\mathrm{b}}$ \\
\hline Diabetes mellitus & $5(6.8)$ & $44(5.7)$ & $0.922^{b}$ \\
\hline \multicolumn{4}{|l|}{ Presumed risk factors } \\
\hline Prior hospitalization & $43(58.9)$ & $458(59.8)$ & 1.030 \\
\hline Antibiotic & $53(72.6)$ & $380(49.6)$ & $0.003^{* *}$ \\
\hline No. of antibiotics $(\geq 3)$ & $14(19.2)$ & $112(14.6)$ & 0.373 \\
\hline Aminoglycosides & $2(2.7)$ & $10(1.3)$ & $0.401^{b}$ \\
\hline$\beta$-lactam $/ \beta$-lactamase inhibitor combinations & $34(46.6)$ & $165(21.5)$ & $<0.001^{* * *}$ \\
\hline Carbapenems & $17(23.3)$ & $127(16.6)$ & 0.365 \\
\hline 3rd and 4th generation cephalosporins & $3(4.1)$ & $10(1.3)$ & $0.320^{b}$ \\
\hline Fluoroquinolones & $24(32.9)$ & $147(19.2)$ & $0.030^{*}$ \\
\hline Glycopeptide & $6(8.2)$ & $38(5.0)$ & $0.440^{\mathrm{b}}$ \\
\hline Tetracyclines & $3(4.1)$ & $47(6.1)$ & $0.681^{b}$ \\
\hline Metronidazole & $4(5.5)$ & $51(6.7)$ & $0.697^{b}$ \\
\hline Vancomycin & $4(5.5)$ & $20(2.6)$ & $0.296^{b}$ \\
\hline Proton pump inhibitors & $45(61.6)$ & $421(55.0)$ & 0.793 \\
\hline Nasogastric tube & $11(15.1)$ & $89(1.6)$ & 0.842 \\
\hline Abdominal surgery & $2(2.7)$ & $29(3.8)$ & $1.000^{\mathrm{b}}$ \\
\hline Chemotherapy & $2(2.7)$ & $37(4.8)$ & $0.947^{b}$ \\
\hline Immunosuppressive agents & $2(2.7)$ & $10(1.3)$ & $0.757^{b}$ \\
\hline \multicolumn{4}{|l|}{ Biological parameters } \\
\hline WBC $\left(\times 10^{9} / \mathrm{L}\right)$ & $6.5(4.54-9.26)$ & $6.23(4.89-8.10)$ & 1.034 \\
\hline WBC count $>9.5 \times 10^{9} / \mathrm{L}$ & $17(23.3)$ & $152(11.8)$ & 0.939 \\
\hline NEU\% & $73.6(64.9-81.4)$ & $64.00(56.5-75.7)$ & $0.035^{*}$ \\
\hline Neutropenia (> 75\%) & $29(39.7)$ & $241(31.5)$ & 0.579 \\
\hline $\mathrm{HB}(\mathrm{g} / \mathrm{L})$ & $116(92-128)$ & $123.00(108-135)$ & 0.655 \\
\hline $\operatorname{PLT}\left(\times 10^{9}\right)$ & $204(138--271)$ & $192.00(155-262)$ & 0.933 \\
\hline ALB $(g / L)$ & $36(30.1-41.1)$ & $40.4(35.3-42.4)$ & 0.420 \\
\hline Hypoalbuminemia (<35 g/L) & $33(45.2)$ & $206(26.9)$ & $0.012^{*}$ \\
\hline AST (U/L) & $19(13-26)$ & $18(15-26)$ & 0.999 \\
\hline CRE (umol/L) & $73(53-100)$ & $65(56-83)$ & 0.728 \\
\hline Serum creatinine $>195 \mu \mathrm{mol} / \mathrm{L}$ & $3(4.1)$ & $10(1.3)$ & $0.420^{b}$ \\
\hline hsCRP (mg/L) & $11.1(4.8-77.7)$ & $4.6(0.7-27.6)$ & 0.426 \\
\hline
\end{tabular}


Table 2 Risk factors assessment of 73 CDI patients and 766 non-CDI controls (Continued)

\begin{tabular}{llll}
\hline Characteristic & TCD infection $(\mathrm{N}=73) \mathrm{n}(\%)$ & Control $(N=766) \mathrm{n}(\%)$ & $P$ value $^{\mathrm{a}}$ \\
\hline Clinical symptoms & & & $57(7.4)$ \\
Abdominal pain & $7(9.6)$ & $36(4.7)$ & 0.938 \\
Fever & $4(5.5)$ & $8(1.0)$ & $0.999^{\mathrm{b}}$ \\
Vomit & $1(1.4)$ & $57(7.4)$ & 0.982 \\
Hematochezia & $6(8.2)$ & 0.978 \\
\hline
\end{tabular}

WBC white blood cell count, NEU neutrophile granulocyte, HB hemoglobin, PLT blood platelet count, ALB albumin, AST glutamic oxalacetic transaminase, CRE

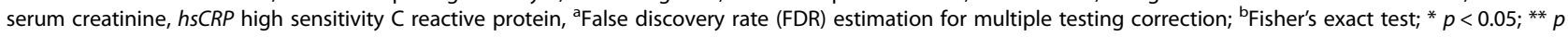
$<0.01$; ${ }^{* * *} p<0.001$

model, antibiotic exposure $(p=0.001, \mathrm{OR}=5.035)$ and kidney disease $(p=0.015, \mathrm{OR}=8.329)$ were the factors remained statistically significant (shown in Table 3). Subgroup analyses of antibiotic treatment showed the use of $\beta$-lactam/ $\beta$-lactamase inhibitor combinations $(p<0.001)$ and fluoroquinolones $(p=0.030)$ were the most relevant antibiotics of CDI.

\section{Two cases of CDT+ CDI}

There were two CDT+ cases observed, with one of them identified as the hypervirulent strain CD027. The CD027 infection case was an 87 years old man. He was admitted to the respiratory department because of severe pneumonia. Notably, he had diarrhea and fever on the day when he was hospitalized. Referring to his medical history, he had been hospitalized in another hospital 12 days before for the heart stent implantation. Treatment details during that period were unavailable. The biological results showed increased WBC $\left(17.8 \times 10^{9}\right.$ cells/ L), NEU\% (91.28\%) and CRE (109 umol/L), but low level of ALB $(26.6 \mathrm{~g} / \mathrm{L})$ when $C$. difficile was detected. Another case was a 64 years old woman, who was hospitalized for heart disease and accompanied with multiple organ dysfunction syndrome (MODS). She did not have diarrhea until 25 days after being hospitalized. During this period, she had nasal feeding tube for 3 days; was exposed to meropenem, cefotaxime/sulbatan, moxifloxacin and proton pump inhibitors. When $C$. difficile was detected, the fecal occult blood test was positive. Similar with CD027 infected case, the biological results showed high level of NEU\% (87.0\%), AST (68 U/L) and CRE (262 umol/L), but low level of ALB $(30.9 \mathrm{~g} / \mathrm{L})$ when TCD was detected.

\section{Molecular epidemiology of the TCD isolates}

As shown in Fig. 3, TCD strains analyzed by MLST were assigned to 21 different STs, including one new genotype, ST467 (clade 1). Most genotypes were found to be from clades 1 and 4, and only two CDT+ strains were from clade 2 (ST1) and clade 3 (ST5), respectively. The most prevalent type was ST54 $(35.6 \%, 26 / 73)$, followed by ST3 $(9.6 \%, 7 / 73)$, ST37 $(8.2 \%, 6 / 73)$, ST35 $(8.2 \%, 6 /$ $73)$, ST $8(6.8 \%, 5 / 73)$ and ST2 $(6.8 \%, 5 / 73)$. The data indicated a correlation between some STs and the toxin genotypes, e.g. all $t c d A-t c d B+$ strains belonged to ST37 (clade 4) except one which belonged to ST81 (clade 4).

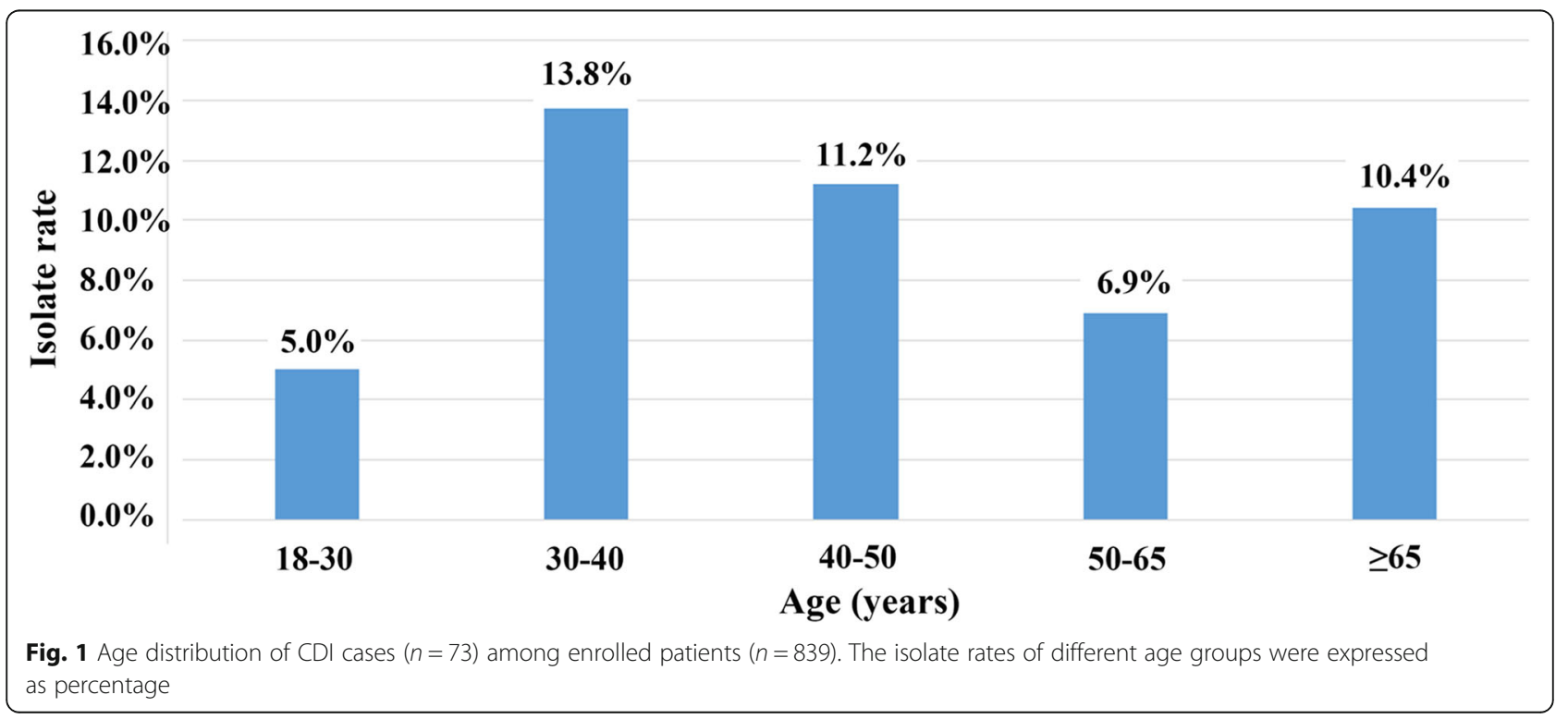




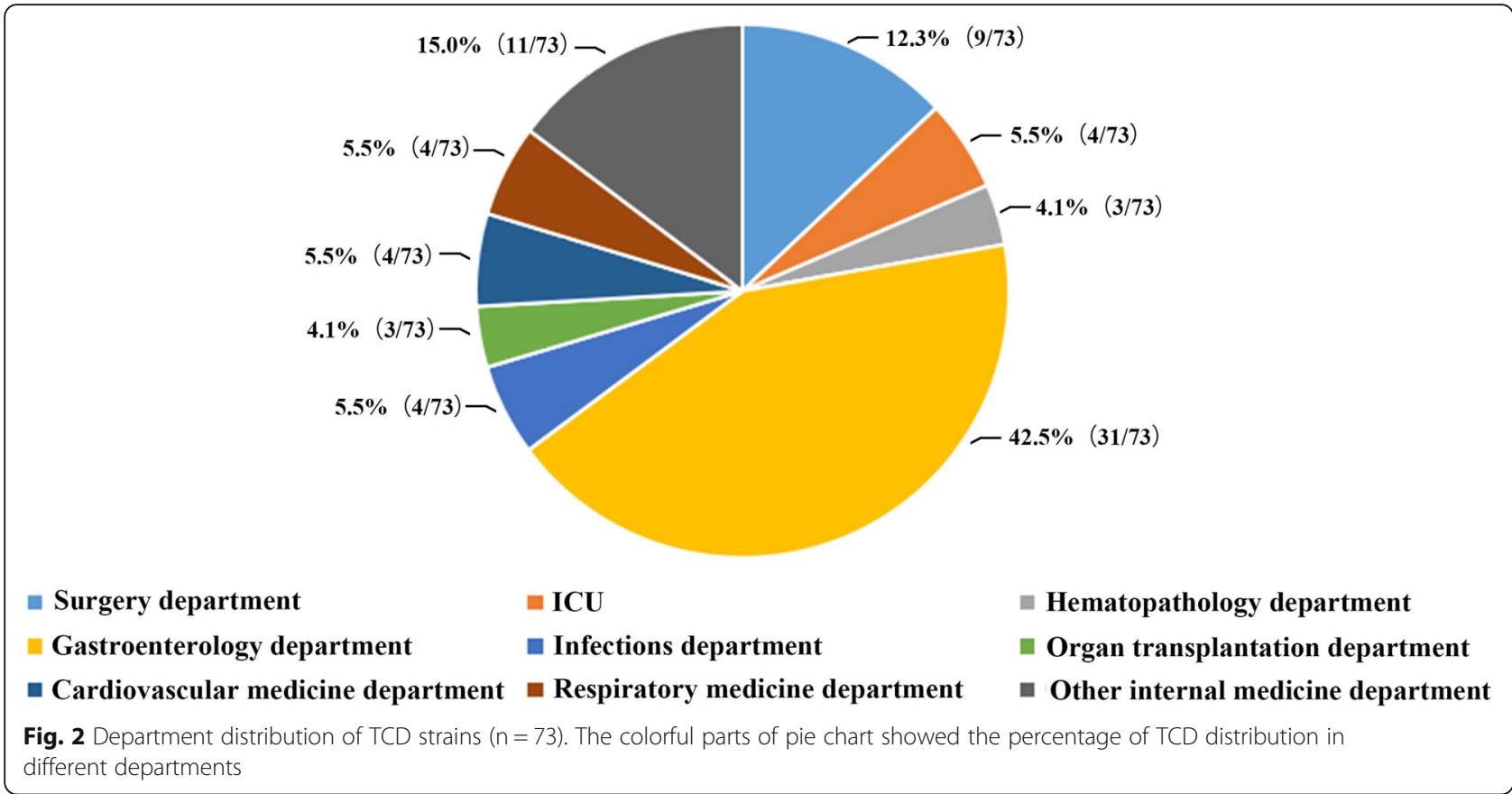

As most TCD $(42.5 \%, 31 / 73)$ were isolated from the gastroenterology department, we specifically analyzed MLST distribution in this department. Overall, 31 TCD strains belonged to 13 STs. Similarly, ST54 was the predominant $(32.3 \%, 10 / 31)$ among them, followed by ST3 (16.1\%, 5/31), ST8 $(9.7 \%, 3 / 31)$ and ST2 (9.7\%, 3/31).

\section{Phylogenetic analysis}

Phylogenetic analysis showed two major (distinct) lineages (Fig. 4). Strains (11.0\%, 8/73) belonging to ST5, ST37 and ST81 constituted one lineage, while the majority $(89.0 \%, 65 / 73)$ belonging to other STs were clustered into another lineage. The newly identified ST467 (clade 1) had $g l y A$ allele changed from allele 1 to allele 5 comparing with ST54 (clade 1). According to the definition of Public Health Ontario, no C. difficile outbreak was observed. Relationships between strains isolated from the gastroenterology department were further analyzed. Among 31 TCD isolation, 19 (61.3\%, 19/31) cases were classified as HCFA CDI. Interestingly, although no

Table 3 Results of multivariate logistic regressions for CDI risk factors assessment

\begin{tabular}{llll}
\hline Parameters & \multicolumn{3}{l}{ Multivariate results } \\
\cline { 2 - 4 } & OR & $95 \% \mathrm{Cl}$ & $P$ \\
\hline Kidney disease & 8.329 & $(1.503,46.156)$ & $0.015^{*}$ \\
Antibiotic exposure & 5.035 & $(1.962,12.921)$ & $0.001^{* *}$ \\
NEU\% & 1.023 & $(0.997,1.050)$ & 0.077 \\
Hypoalbuminemia & 1.443 & $(0.676,3.084)$ & 0.343 \\
\hline OR Odds ratios, 95\% Cl 95\% confidence intervals, ${ }^{*} p<0.05 ;{ }^{* *} p<0.01$
\end{tabular}

outbreak was detected, three HCFA cases (TCD04, TCD05 and TCD22, all belonging to ST54) were found among patients who occupied the same bed during $2016 / 08 / 14$ to $2016 / 10 / 08$.

\section{Resistance of the TCD strains}

The resistant results to 14 antibiotics amongst TCD strains were shown in Table 4 (raw data shown in Additional file 2). The most prevalent resistance was detected for ciprofloxacin $(71.2 \%, 52 / 73)$, followed by $61.6 \%$ (45/73) for erythromycin, 53.4\% (39/73) for clindamycin and $45.2 \%$ (33/73) for fusidic acid. Resistance to tetracycline, moxifloxacin and levofloxacin was less common $(<30 \%)$. However, all tested isolates were sensitive to metronidazole, piperacillin/tazobactam, vancomycin, rifampicin and linezolid. Among the fluoroquinolones, resistance to ciprofloxacin $(71.2 \%, 52 / 73)$ was higher than that of levofloxacin $(16.4 \%, 12 / 73)$ and moxifloxacin $(12.3 \%, 9 / 73)$. Almost all the moxifloxacin resistant strains $(88.9 \%, 8 / 9)$ showed resistant to ciprofloxacin and levofloxacin (seen in the Additional file 2). Meanwhile, MIC values of clindamycin $\left(\mathrm{MIC}_{90}>128 \mu \mathrm{g} /\right.$ $\mathrm{ml})$ and erythromycin $\left(\mathrm{MIC}_{90}>128 \mu \mathrm{g} / \mathrm{ml}\right)$ were rather high. 39 (53.4\%, 39/73) TCD isolates were MDR, with two isolates showing intermediate activities to meropenem and chloramphenicol, respectively. As expected, CD027 isolate showed high resistance to fluoroquinolones (ciprofloxacin, MIC> $128 \mu \mathrm{g} / \mathrm{ml}$; levofloxacin, MIC $>128 \mu \mathrm{g} / \mathrm{ml}$; and moxifloxacin, $\mathrm{MIC}=32 \mu \mathrm{g} / \mathrm{ml}$ ). Although the drug susceptibility results of three ST54 strains isolated from patients who once shared the same 


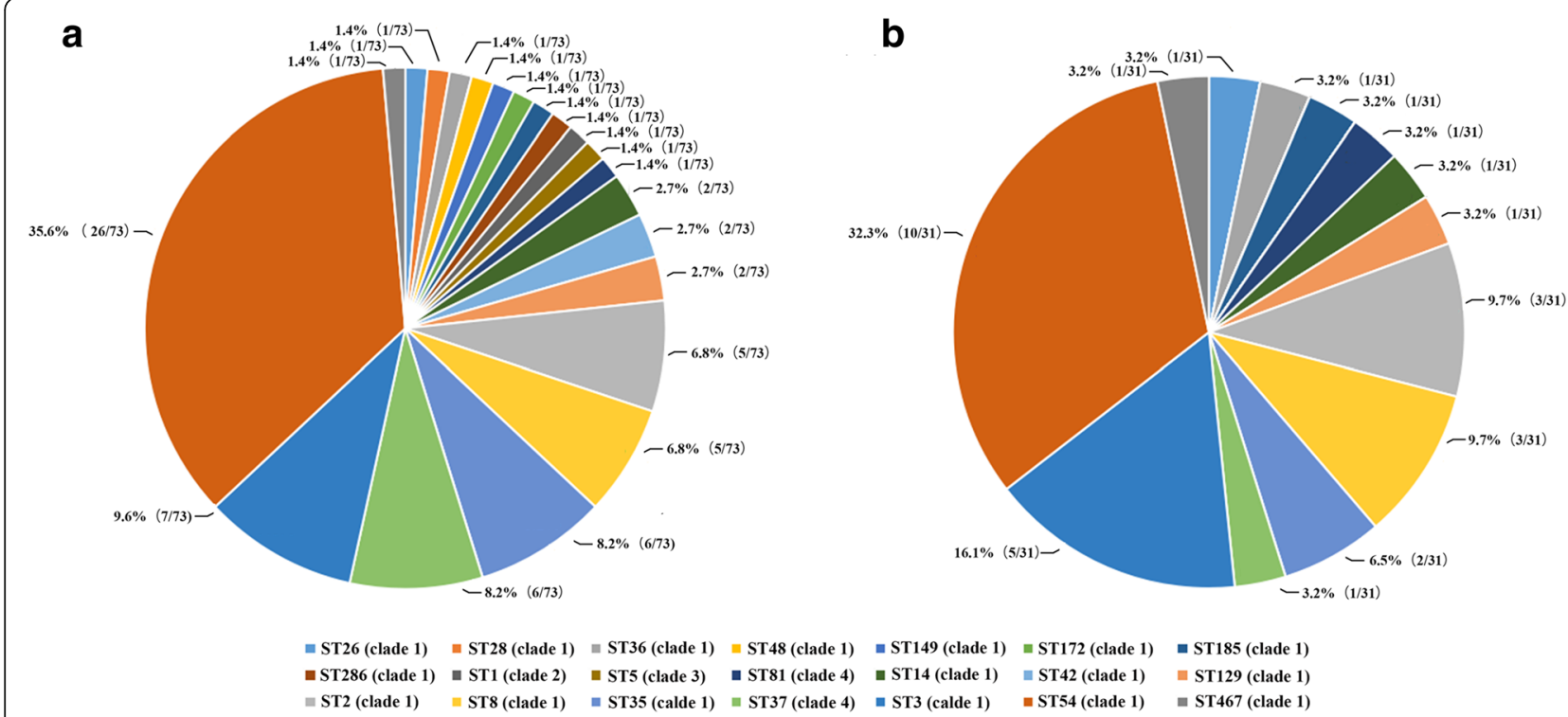

Fig. 3 MLST distribution of TCD strains $(n=73)$. a MLST distribution of all isolated TCD strains $(n=73)$. $\mathbf{b}$ MLST distribution of TCD strains isolated from the gastroenterology department $(n=31)$. The colorful parts of pie chart showed the percentage of different STs

bed were different, two of them were MDR. Additionally, most of the ST37 strains were sensitive to the antimicrobial agents tested, and only one isolate was MDR.

\section{Gyrase mutations}

Among 53 (72.6\%, 53/73) TCD strains showing high resistance to quinolones ( $\mathrm{MIC} \geq 8 \mu \mathrm{g} / \mathrm{ml}$ to ciprofloxacin or levofloxacin or moxifloxacin), only 9 (17.0\%; 9/53) isolates were moxifloxacin resistant (shown in Table 5). However, sequence analysis demonstrated that all moxifloxacin resistant strains had mutations in GyrA (Thr82 $\rightarrow$ Ile), with one both having mutation in GyrB $($ Ser366 $\rightarrow$ Ala) (sequencing results shown in Additional file 3).

\section{Discussion}

CDI has come to prominence in the last decade and is regarded as the leading cause of nosocomial diarrhea among adults in North America and Europe [2]. However, little is known about the epidemiology of CDI in China, especially in its central part [11,31]. In the present study, 839 adults with suspicion of CDI were evaluated to investigate the prevalence, risk factors, molecular characteristics and antibiotic resistance patterns of CDI. Meanwhile, the first isolation of CD027 in central China was reported.

\section{Prevalence of $C D I$ and cases of CDT+ isolates}

A multicenter study by the Centers for Disease Control (CDC) in the United States revealed the positive rate of CDI ranging from 7 to 20\% [32].The prevalence of CDI in our study was $8.7 \%$ (73/839), same to Chen et al.'s result [21], but a little lower than another study conducted in eastern China (10.0\%) [15]. Searching through the PubMed, systematic epidemiological studies about CDI in Wuhan is extremely rare, the only one founded was Galaydick et al.'s research published in 2015, which indicated the overall prevalence of C. difficile was $28 \%$ [33]. Although both studies performed PCR method for TCD detection, the demographic data of enrolled patients were different and those who tested positive tended to be older than ours (with a median age of 72 years old VS 52 years old). A meta-analysis showed the pooled incidence of TCD among diarrheal patients in Mainland China was $14 \%$, with a high level of heterogeneity between the estimated rates [31]. This further indicated the influence of different regions in the prevalence of CDI.

$T c d A-t c d B+$ strains, most belonging to ST37, has been recognized as a potential epidemic strain in China [12]. Different with other reports [29, 34] but similar with Salazar et al.'s result [35], $t c d A-t c d B+$ strains were not common in the present study, only accounting for 9.6\% (7/73) of the $73 \mathrm{TCD}$ isolates; and $t c d A+t c d B+$ strains, accounting for $90.4 \%$ (66/73), was the dominant type. It was noteworthy that two CDT+ isolates were observed in our study, and one of them was finally identified as CD027, which was sparsely reported in China. Both cases infected with CDT+ strains (ST1 and ST5), owned high risk factors of CDI (advanced age, antibiotic exposure, abnormal biological results and accompanied with other sever comorbidities). Since 2003, the first outbreak of CD027 (NAP1/BI/027) reported in North America [36], cases have been reported worldwide. 


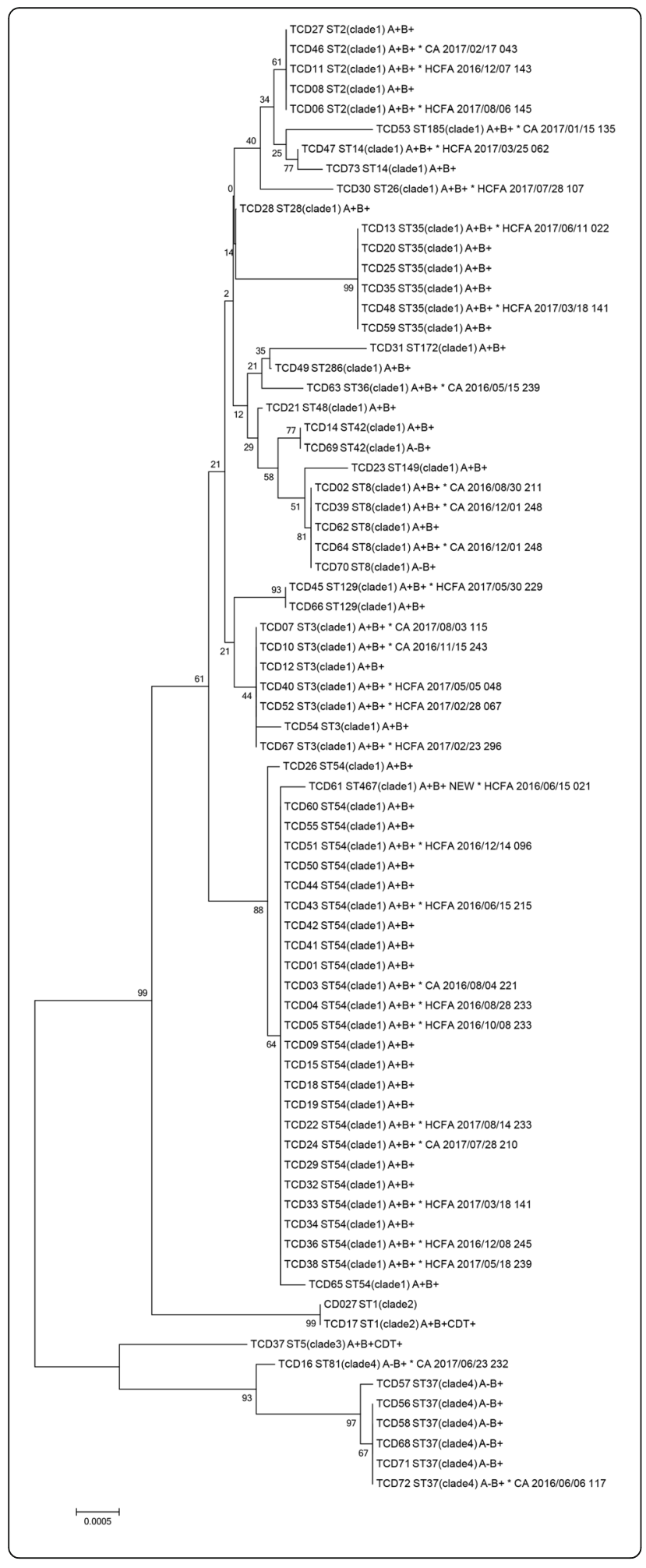

Fig. 4 Phylogenetic tree of TCD strains $(n=73)$. Bootstraps were generated using 1000 replicates and bootstrap values for the cluster were shown on respective branches. ST, clade and toxin types were presented after each TCD strains. For strains isolated from the gastroenterology department, additional information (e.g. onset of diarrhea, admission date and bed number) were presented. CD027 was acted as the reference strain. $A, t c d A ; B, t c d B ; C D T$, binary toxin positive; NEW, new ST type; CA, community-acquired; HCFA, healthcare facility-associated; ${ }^{*}$, isolated from the gastroenterology department

Nevertheless, there was no report in mainland China until Wang et al. [37] identified the first isolation of CD 027 in late 2013. Although, CD027 infected cases have been already described in Hongkong, Beijing and Guangzhou [37-39], this is the first report of CD027 identified in Wuhan, Central China, which indicated the importance to carry out active surveillance for the emergence of hypervirulent C. difficile.

\section{Risk factors of CDI}

Practice guidelines indicated the two biggest risk factors of CDI were exposure to antibiotics and the organism [40]; Gualtero et al.'s research [41] demonstrated chronic kidney disease was the most common comorbidities associated with CDI. In concurrence with these studies, the multivariate regression model indicated that prior use of antimicrobial agents $(p=0.001, \mathrm{OR}=5.035)$ and kidney disease $(p=0.015$, OR $=8.329)$ were closely related to CDI. To date, several antibiotics have been associated with CDI development in hospitals, such as cephalosporins, clindamycin, penicillins and fluoroquinolones [42]. Among them, quinolones are one of the most common antimicrobial agents used in China, which has been identified as a prominent risk factor for CDI and has been associated with CD027 outbreaks [43]. In agreement with this point, fluoroquinolones $(p$ $=0.030$ ) was found increasing the risk of CDI in our study. Additionally, it was observed that use of $\beta$-lactam/ $\beta$-lactamase inhibitor combinations $(p<0.001)$ also associated with CDI, which was consistent with Pakyz et al.'s [44] and Vishwanath et al.'s [45] results. However, Dubberke et al. [46] got the opposite result, which indicated $\beta$-lactam $/ \beta$-lactamase inhibitor combinations were associated with a loss of $C$. difficile colonization. Different situation of antibiotic usage might contribute to different results, which implied additional studies are needed to solve the controversy.

Traditionally, risk factors for CDI include old age ( $\geq 65$ years), antibiotic use, exposure to healthcare settings and various comorbidities or preexisting conditions [47]. Nonetheless, in the present study, some variables (age, gastrointestinal disease, and proton pump inhibitors) show no significant associations. Jin et al. found the age threshold as a risk factor for CDI patients in 
Table 4 MICs of 14 antimicrobial agents for 73 TCD isolates by agar dilution method

\begin{tabular}{|c|c|c|c|c|c|c|c|}
\hline \multirow[t]{2}{*}{ Antimicrobial agent } & \multirow{2}{*}{$\begin{array}{l}\text { Breakpoint } \\
\text { of resistant } \\
(\mathrm{ug} / \mathrm{ml})\end{array}$} & \multicolumn{3}{|c|}{$\mathrm{MIC}(\mathrm{ug} / \mathrm{ml})$} & \multicolumn{3}{|c|}{ No. (\%) of isolates } \\
\hline & & $\begin{array}{l}\mathrm{MIC}_{50} \\
(\mathrm{ug} / \mathrm{ml})\end{array}$ & $\begin{array}{l}\mathrm{MIC}_{90} \\
(\mathrm{ug} / \mathrm{ml})\end{array}$ & $\begin{array}{l}\text { Range } \\
\text { (ug/ml) }\end{array}$ & Sensitive & Intermediate & Resistant \\
\hline Metronidazole & $\geq 32$ & 0.25 & 0.25 & $\leq 0.03-1$ & $73(100)$ & $0(0)$ & $0(0)$ \\
\hline Piperacillin/tazobactam & $\geq 128 / 4$ & 4 & 8 & $\leq 0.03-16$ & $73(100)$ & $0(0)$ & $0(0)$ \\
\hline Meropenem & $\geq 16$ & 1 & 2 & $\leq 0.03-8$ & 72 (98.6) & $1(1.4)$ & $0(0)$ \\
\hline Tetracycline & $\geq 16$ & 0.25 & 16 & $\leq 0.03-32$ & $54(74.0)$ & $9(12.3)$ & $10(13.7)$ \\
\hline Clindamycin & $\geq 8$ & 8 & $>128$ & $\leq 0.03->128$ & $27(37.0)$ & $7(9.6)$ & $39(53.4)$ \\
\hline Erythromycin & $\geq 8$ & 128 & $>128$ & $\leq 0.03->128$ & $28(38.4)$ & - & $45(61.6)$ \\
\hline Chloramphenicol & $\geq 32$ & 4 & 8 & $\leq 0.03-16$ & 72 (98.6) & $1(1.4)$ & $0(0)$ \\
\hline Vancomycin & $\geq 32$ & 0.5 & 1 & $\leq 0.03-16$ & $73(100)$ & - & $0(0)$ \\
\hline Rifampicin & $\geq 32$ & $\leq 0.03$ & $\leq 0.03$ & $\leq 0.03-1$ & $73(100)$ & - & $0(0)$ \\
\hline Levofloxacin & $\geq 8$ & 4 & 64 & $\leq 0.03->128$ & 61 (83.6) & - & $12(16.4)$ \\
\hline Ciprofloxacin & $\geq 8$ & 8 & 32 & $\leq 0.03->128$ & $21(28.8)$ & - & $52(71.2)$ \\
\hline Moxifloxacin & $\geq 8$ & 2 & 8 & $\leq 0.03-32$ & 64 (87.7) & $0(0)$ & $9(12.3)$ \\
\hline Fusidic acid & $>0.5$ & 0.5 & 8 & $\leq 0.03-16$ & $40(54.8)$ & - & $33(45.2)$ \\
\hline Linezolid & $>4$ & 2 & 4 & $\leq 0.03-4$ & 73 (100) & - & $0(0)$ \\
\hline
\end{tabular}

eastern China to be lower than the age thresholds seen in developed countries [15]. Meanwhile, reports on CA CDI have increased and revealed alarming trends among young people, who were not at high risk according to the traditional factors [48]. In this study, the mean age of diarrhea patients was only 51 years and $21.8 \%$ (183/ 839) patients had CA diarrhea. Supported by the above views, the difference of demographic distribution might affect the result of logistic regression and explain the reasons for the discrepancy of risk factors.

\section{Molecular characterization of TCD}

Genotyping by MLST identified 21 different STs including one new ST (ST467). This diversity is likely due to the different geographical location of patients hospitalized in our hospital (which treats patients from the six surrounding provinces). Although no isolate belonged to
ST11 (usually correlated with hypervirulent ribotype078), one hypervirulent $C$. difficile ST1 (CD027) was observed. Meanwhile, in accord with Chen et al.'s result [21], ST54 (35.6\%, 26/73) was the dominant type in our study. Reports from Shanghai [49] and Guangzhou [34] demonstrated all $t c d A-t c d B+$ strains were ST37 (clade 4), while a study from Hangzhou found they were assigned to different STs. In the present study, $t c d A-t c d B+$ isolates were from two different STs (ST37 and ST81), but most of them $(85.7 \%, 6 / 7)$ belonged to ST37.

The novel ST467 (clade 1) was isolated from a male patient in the gastroenterology department. Although phylogenetic analysis suggested that ST467 (clade 1) might evolve from ST54 (clade 1), no similar antimicrobial resistance profiles were observed with ST54 (clade 1) strains isolated from this department (seen in the Additional file 2).

Table 5 The MICs of fluoroquinolones and gyrase mutations for 9 isolates with moxifloxacin resistance

\begin{tabular}{lllll}
\hline $\begin{array}{l}\text { Number } \\
\text { of } \\
\text { strains }\end{array}$ & MIC $(\mathrm{ug} / \mathrm{ml})$ & & Gyrase mutations \\
\cline { 2 - 5 } & Ciprofloxacin & 128 & Levofloxacin & GyrA \\
\hline TCD 10 & 0.125 & $>128$ & 16 & Thr82lle \\
TCD 17 & $>128$ & $>128$ & 32 & Thr82lle \\
TCD 27 & 64 & 16 & 8 & Thr82lle \\
TCD 28 & 32 & $>128$ & 16 & Thr82lle \\
TCD 42 & 128 & 16 & 32 & Thr82lle \\
TCD 53 & 8 & 64 & 8 & Thr82lle \\
TCD 54 & 64 & $>128$ & 32 & Thr82lle \\
TCD 58 & 128 & 64 & 32 & Thr82lle \\
TCD 59 & 64 & 32 & Thr82lle \\
\hline
\end{tabular}


In the present study, most TCD strains $(42.5 \%, 31 / 73)$ were isolated from the gastroenterology department. Although no outbreak were observed, there were three HCFA cases (all belonging to ST54) sharing the same bed during two months. As occupying the room of a former patient with CDI contributes to an increased risk of acquiring $C$. difficile [50], effective measures are necessary to prevent the nosocomial transmission of CDI.

\section{Antimicrobial agents-resistant rate among TCD strains}

Antimicrobial resistance of $C$. difficile is highly variable in different populations and countries, ranging from 0 to $100 \%$ [51]. Specific antibiotic resistance pattern was also observed in our study. A meta-analysis results which included several studies and a large number of samples in mainland China showed the rates of $C$. difficile resistance to ciprofloxacin, clindamycin and erythromycin are higher than in other counties [31]. In our study, TCD showed highest resistance to ciprofloxacin $(71.2 \%, 52 /$ $73)$, followed by erythromycin $(61.6 \%, 45 / 73)$ and clindamycin $(53.4 \%, 39 / 73)$, but lower than above results (98.3\% for ciprofloxacin, $80.2 \%$ for erythromycin, and 81.7\% for clindamycin). However, consistent with this study, none of isolated strains were resistant to metronidazole and vancomycin. Metronidazole and vancomycin are the first-line antibiotics for mild to moderate CDI and severe infection, respectively [52]; although resistance to metronidazole and vancomycin is not yet a major issue in china, reduced susceptibility to these antibiotics has been gradually increasing [53], which highlighted the need for constant surveillance. The MDR in our study was similar with Spigaglia et al.'s result (53.4\% VS 55\%) conducted in European [54], but higher than Putsathit et al.'s (53.4\% VS 21.9\%) in Thailand [55]. Meeting our expectation, CD027 isolate showed high resistance to fluoroquinolones in the present study. Most ST37 isolates were sensitive to tested antibiotics in our setting. As $t c d A-t c d B+$ isolates has been associated with increased antibiotic resistance in many studies [56], further research is needed to solve this discrepancy. A present study indicated the diversity of antimicrobial resistance in these strains [34], therefore, the small number of ST37 isolates in the present study and the regional diversity might be the possible causes.

A recent study showed the resistance rate of moxifloxacin in different regions ranging from 2 to 64\% [57]. In the present study, the resistance rate to moxifloxacin was $12.3 \%$ (9/73), lower than Chen et al.' [58] and Jin et al.'s results [15] in China. Resistance to fluoroquinolones is generally caused by two main mechanisms, and the principal mechanism of quinolone resistance in $C$. difficile is determined by mutations in the quinolone resistance-determining region (QRDR) of either DNA gyrase subunit GyrA or GyrB. Up to now, there are five different amino acid substitutions in GyrA (Thr82 $\rightarrow$ Ile, Thr82 $\rightarrow$ Val, Asp71 $\rightarrow$ Val, Asp81 $\rightarrow$ Asn, and Ala118 $\rightarrow$ Thr) and six substitutions in GyrB (Asp426 $\rightarrow$ Val, Asp426 $\rightarrow$ Asn, Arg447 $\rightarrow$ Leu, Arg447 $\rightarrow$ Lys, Ser366 $\rightarrow$ Ala, and Ser416 $\rightarrow$ Ala) in clinical isolates [59]. Concordance with other studies $[58,59]$, Thr82 $\rightarrow$ Ile in GyrA, which also characterises the hypervirulent epidemic clone CD027, is the most frequent amino acid change in the present study. Only one strain, showing high resistant to all tested fluoroquinolones, harbored both GyrA (Thr82 $\rightarrow$ Ile) and GyrB (Ser366 $\rightarrow$ Ala). However, Ser366 $\rightarrow$ Ala is not thought to have a key role in resistance since they are also detected in susceptible strains [51].

\section{Limitations}

This study also had some limitations. First of all, we enrolled all the hospitalized adults when doctor suspected of CDI, which might have differences in physician awareness of CDI between hospitals and caused bias. Meanwhile, we used PCR method for TCD detection and didn't screened other diarrheal pathogens, which might misidentify $C$. difficile associated and non-CDI associated diarrhea patients. Strictly speaking, CDI is defined as the acute onset of diarrhea with TCD and no other documented cause for diarrhea [7], while many enrolled patients in the present study were CA diarrhea $(21.8 \%, 183 / 839)$ and most were admitted in the AprilJune $(41.7 \%, 350 / 839)$, indicating the high-risk of diarrhea caused by other pathogens like rotavirus and salmonella $[60,61]$. Therefore, the two step algorithms (e.g. screen with nucleic acid amplification test and then performed Toxin A/B EIA test), currently more recommended methods for rapid diagnosis of CDI [2], should be applied. Secondly, some studies have found that the prevalence of asymptomatic colonization with $C$. difficile is high among adult inpatients [62, 63], while we didn't detect $C$. difficile in asymptomatic patients and the environment to further explore the possible transmission of CDI. Thirdly, we only studied the $C$. difficile obtained from our setting, a multicenter study should be conducted to represent the characterization of $C$. difficile in central China.

\section{Conclusion}

CDI has generally remained poorly understood in China. The present study carried a systematic epidemiological survey of CDI, and reported the isolation of CD027 for the first time in central China. Several meaningful information were provided here. $T c d A-t c d B+$ strains were not the dominant, and most CDI in our setting were caused by $t c d A+t c d B+$ strains. Antibiotic exposure and kidney disease were most relevant factors for CDI. Although, 
reports about reduced susceptibility to common antibiotics has been gradually increasing, up to now, the primary antibacterial agents, metronidazole and vancomycin, are still suitable for empiric treatment against CDI in our hospital. Thr82 $\rightarrow$ Ile in GyrA is the most frequent amino acid change in moxifloxacin resistant isolates. CD027 isolate exhibited high resistant to fluoroquinolones and led to severe symptoms. To our knowledge, it is the first CD027 isolate identified in Hubei China, which deserves our vigilance. Further surveillance is urgent to monitor the emergence of specific highly virulent clones and the antibiotic resistance patterns in China.

\section{Additional files}

Additional file 1: Gel electrophoresis fingerprint of CD027 ribotyping.

(TIF $82 \mathrm{~kb}$ )

Additional file 2: Raw data of MIC. (XLSX $256 \mathrm{~kb}$ )

Additional file 3: Sequencing results for GyrA and GyrB genes. (DOCX $15 \mathrm{~kb}$ )

\section{Abbreviations}

ALB: Albumin; AST: Glutamic oxalacetic transaminase; CA: Communityacquired; CD027: $C$. difficile ribotype 027; CDC: the Centers for Disease Control; CDI: Clostridium difficile infection; CDT: Binary toxin; Cls: Confidence intervals; CLSI: Clinical and Laboratory Standards Institute; CRE: Serum creatinine; EUCAST: European Committee on Antimicrobial Susceptibility Testing; HB: hemoglobin; HCFA: Healthcare facility-associated; hsCRP: High sensitivity $\mathrm{C}$ reactive protein; MALDI-MS: Matrix-assisted laser desorption/ ionization time of flight mass spectrometry; MDR: Multidrug resistant; MICs: Minimum inhibitory concentrations; MLST: Multilocus sequence typing; MODS: Multiple organ dysfunction syndrome; NEU\%: Percentage of neutrophile granulocyte; NJ: Neighbor-joining; ORs: Odds ratios; PLT: Blood platelet count; QRDR: Quinolone resistance-determining region; STs: Sequence types; TCD: Toxigenic C. difficile; WBC: Blood cell count

\section{Acknowledgments}

The authors would like to thank Jie Lei and the clinical and laboratory staff of the Tongji hospital, Wuhan, China, for facilitating the collection of the stool samples.

\section{Funding}

This work was supported by research grants from the National Mega Project on Major Infectious Disease Prevention (2017ZX10103005-007). The funders had no role in study design, data collection and analysis, decision to publish, or preparation of the manuscript.

\section{Availability of data and materials}

The data supporting the conclusions of this article are included within the article and its Additional files 1, 2 and 3.

\section{Authors' contributions}

ZS and XZ designed the study. JY and QL were responsible for the patients recruitment, samples collection and transport to the laboratory. $Y Z$ and JY were in charge of laboratory procedures. $Y L$ did the statistical analysis. $Y Z$ and LM wrote the manuscript. All authors read and approved the final manuscript.

\section{Ethics approval and consent to participate}

The study protocol was approved by the Tongji Hospital ethics committee for research in health. Informed written consent was obtained from the patient before inclusion in the study.
Consent for publication

Not applicable.

\section{Competing interests}

the authors declare that they have no competing interests.

\section{Publisher's Note}

Springer Nature remains neutral with regard to jurisdictional claims in published maps and institutional affiliations.

\section{Author details}

${ }^{1}$ Department of Laboratory Medicine, Zhejiang Provincial People's Hospital, People's Hospital of Hangzhou Medical College, Zhejiang 310014, Hangzhou, China. ${ }^{2}$ Department of Laboratory Medicine, Tongji Hospital, Tongji Medical College, Huazhong University of Science and Technology, No. 1095 Jiefang Road, Wuhan 430030, China.

Received: 7 March 2018 Accepted: 21 February 2019

Published online: 07 March 2019

\section{References}

1. Zhou FF, Wu S, Klena JD, Huang HH. Clinical characteristics of Clostridium difficile infection in hospitalized patients with antibiotic-associated diarrhea in a university hospital in China. European journal of clinical microbiology \& infectious diseases : official publication of the European Society of Clinical Microbiology. 2014;33(10):1773-9.

2. Martin JS, Monaghan TM, Wilcox MH. Clostridium difficile infection: epidemiology, diagnosis and understanding transmission. Nat Rev Gastroenterol Hepatol. 2016;13(4):206-16.

3. Lessa FC, Mu Y, Bamberg WM, Beldavs ZG, Dumyati GK, Dunn JR, Farley MM, Holzbauer SM, Meek JI, Phipps EC, et al. Burden of Clostridium difficile infection in the United States. N Engl J Med. 2015;372(9):825-34.

4. Clostridium difficile infection in Europe_a CDI Europe report 2013. Available at: http://www.multivu.com/assets/60637/documents/60637-CDI-HCPReport-original.pdf.

5. Leffler DA, Lamont JT. Clostridium difficile infection. N Engl J Med. 2015; 372(16):1539-48.

6. Elliott B, Androga GO, Knight DR, Riley TV. Clostridium difficile infection: evolution, phylogeny and molecular epidemiology. Infection, genetics and evolution : journal of molecular epidemiology and evolutionary genetics in infectious diseases. 2017:49:1-11.

7. Cohen SH, Gerding DN, Johnson S, Kelly CP, Loo VG, McDonald LC, Pepin J, Wilcox $\mathrm{MH}$. Clinical practice guidelines for Clostridium difficile infection in adults: 2010 update by the society for healthcare epidemiology of America (SHEA) and the infectious diseases society of America (IDSA). Infect Control Hosp Epidemiol. 2010;31(5):431-55.

8. Asempa TE, Nicolau DP. Clostridium difficile infection in the elderly: an update on management. Clin Interv Aging. 2017;12:1799-809.

9. Huang $\mathrm{H}$, Wu S, Wang M, Zhang Y, Fang H, Palmgren AC, Weintraub A, Nord CE. Clostridium difficile infections in a Shanghai hospital: antimicrobial resistance, toxin profiles and ribotypes. Int J Antimicrob Agents. 2009;33(4): 339-42.

10. Lihua Z, Danfeng D, Cen J, Xuefeng W, Yibing P. Clinical characterization and risk factors of Clostridium difficile infection in elderly patients in a Chinese hospital. Journal of infection in developing countries. 2015;9(4): $381-7$.

11. Collins DA, Hawkey PM, Riley TV. Epidemiology of Clostridium difficile infection in Asia. Antimicrob Resist Infect Control. 2013;2(1):21.

12. Du P, Cao B, Wang J, Li W, Jia H, Zhang W, Lu J, Li Z, Yu H, Chen C, et al. Sequence variation in tcdA and tcdB of Clostridium difficile: ST37 with truncated tcdA is a potential epidemic strain in China. J Clin Microbiol. 2014;52(9):3264-70.

13. Deshpande A, Borren NZ, Ghadermarzi S, Hutfless S, Ananthakrishnan AN. The emergence of Clostridium difficile infection in Asia: a systematic review and meta-analysis of incidence and impact. PLoS One. 2017;12(5):e0176797.

14. Kim J, Pai H, Seo MR, Kang JO. Clinical and microbiologic characteristics of tcdA-negative variant Clostridium difficile infections. BMC Infect Dis. 2012;12: 109.

15. Jin D, Luo Y, Huang C, Cai J, Ye J, Zheng Y, Wang L, Zhao P, Liu A, Fang W et al: Molecular Epidemiology of Clostridium difficile Infection in Hospitalized Patients in Eastern China. 2017, 55(3):801-810. 
16. He M, Miyajima F, Roberts P, Ellison L, Pickard DJ, Martin MJ, Connor TR, Harris SR, Fairley D, Bamford KB, et al. Emergence and global spread of epidemic healthcare-associated Clostridium difficile. Nat Genet. 2013;45(1): 109-13.

17. Eyre DW, Cule ML, Wilson DJ, Griffiths D, Vaughan A, O'Connor L, Ip CLC, Golubchik T, Batty EM, Finney JM, et al. Diverse sources of C. Difficile infection identified on whole-genome sequencing. N Engl J Med. 2013; 369(13):1195-205

18. McFarland LV, Ozen M, Dinleyici EC, Goh S. Comparison of pediatric and adult antibiotic-associated diarrhea and Clostridium difficile infections. World J Gastroenterol. 2016;22(11):3078-104.

19. Testing, surveillance andmanagement of Clostridium difficile in all healthcare settings. Available at:https://www.publichealthontario.ca/-/media/ documents/cdiff-testing-surveillance-management.pdf?la=en. Accessed 2 Feb 2017.

20. Tian L, Zhu X, Chen Z, Liu W, Li S, Yu W, Zhang W, Xiang X, Sun Z. Characteristics of bacterial pathogens associated with acute diarrhea in children under 5 years of age: a hospital-based cross-sectional study. BMC Infect Dis. 2016:16:253.

21. Chen YB, Gu SL, Wei ZQ, Shen P, Kong HS, Yang Q, Li LJ. Molecular epidemiology of Clostridium difficile in a tertiary hospital of China. J Med Microbiol. 2014;63(Pt 4):562-9.

22. Persson $\mathrm{S}$, Jensen JN, Olsen KE. Multiplex PCR method for detection of Clostridium difficile tcdA, tcdB, cdtA, and $c d t B$ and internal in-frame deletion of tcdC. J Clin Microbiol. 2011;49(12):4299-300.

23. Cheng Y, Du P, Chen C, Yan S, Jia H, Wang J, Yan Q, Feng H, Lu J. Toxin Anegative, toxin B-positive Clostridium difficile infection diagnosed by polymerase chain reaction. Infect Control Hosp Epidemiol. 2011;32(5):520-2.

24. Kato H, Kato N, Watanabe K, Iwai N, Nakamura H, Yamamoto T, Suzuki K, Kim SM, Chong Y, Wasito EB. Identification of toxin A-negative, toxin Bpositive Clostridium difficile by PCR. J Clin Microbiol. 1998;36(8):2178-82.

25. Griffiths D, Fawley W, Kachrimanidou M, Bowden R, Crook DW, Fung R, Golubchik T, Harding RM, Jeffery KJ, Jolley KA, et al. Multilocus sequence typing of Clostridium difficile. J Clin Microbiol. 2010;48(3):770-8.

26. Bidet $P$, Barbut $F$, Lalande V, Burghoffer B, Petit JC. Development of a new PCR-ribotyping method for Clostridium difficile based on ribosomal RNA gene sequencing. FEMS Microbiol Lett. 1999;175(2):261-6.

27. CLSI. Performance standards for antimicrobial susceptibility testing. $27^{\text {th }} \mathrm{ed}$. CLSI supplement, M100. Wayne, PA: Clinical and Laboratory Standards Institute; 2017.

28. Chen R, Feng Y, Wang X, Yang J, Zhang X, Lu X, Zong Z. Whole genome sequences of three clade 3 Clostridium difficile strains carrying binary toxin genes in China. Sci Rep. 2017;7:43555.

29. Gao Q, Wu S, Huang H, Ni Y, Chen Y, Hu Y, Yu Y. Toxin profiles, PCR ribotypes and resistance patterns of Clostridium difficile: a multicentre study in China, 2012-2013. Int J Antimicrob Agents. 2016;48(6):736-9.

30. Huang $H$, Weintraub A, Fang $H$, Wu S, Zhang $Y$, Nord CE. Antimicrobial susceptibility and heteroresistance in Chinese Clostridium difficile strains. Anaerobe. 2010;16(6):633-5.

31. Tang C, Cui L, Xu Y, Xie L, Sun P, Liu C, Xia W, Liu G. The incidence and drug resistance of Clostridium difficile infection in mainland China: a systematic review and meta-analysis. Sci Rep. 2016;6(1).

32. Cohen J, Limbago B, Dumyati G, Holzbauer S, Johnston H, Perlmutter R, Dunn J, Nadle J, Lyons C, Phipps E, et al. Impact of changes in Clostridium difficile testing practices on stool rejection policies and C. Difficile positivity rates across multiple laboratories in the United States. J Clin Microbiol. 2014; 52(2):632-4.

33. Galaydick J, Xu Y, Sun L, Landon E, Weber SG, Sun D, Zhou J, Sherer R. Seek and you shall find: prevalence of Clostridium difficile in Wuhan, China. Am J Infect Control. 2015;43(3):301-2.

34. Lidan C, Linhai L, Yang L, Zhaohui S, Xiaoyan H, Yuling S. Molecular characterization and antimicrobial susceptibility of tcdA-negative Clostridium difficile isolates from Guangzhou, China. Diagn Microbiol Infect Dis. 2016;84(4):361-5.

35. Salazar CL, Reyes C, Atehortua S, Sierra P, Correa MM, Paredes-Sabja D, Best E, Fawley WN, Wilcox M, Gonzalez A. Molecular, microbiological and clinical characterization of Clostridium difficile isolates from tertiary care hospitals in Colombia. PLoS One. 2017:12(9):e0184689.

36. Kuijper EJ, Barbut F, Brazier JS, Kleinkauf N, Eckmanns T, Lambert ML, Drudy D, Fitzpatrick F, Wiuff C, Brown DJ, et al. Update of Clostridium difficile infection due to PCR ribotype 027 in Europe, 2008. Euro surveillance : bulletin Europeen sur les maladies transmissibles = European communicable disease bulletin. 2008;13(31).

37. Wang P, Zhou Y, Wang Z, Xie S, Zhang T, Lin M, Li R, Tan J, Chen Y, Jiang B. Identification of Clostridium difficile ribotype 027 for the first time in mainland China. Infect Control Hosp Epidemiol. 2014;35(1):95-8.

38. Cheng VC, Yam WC, Chan JF, To KK, Ho PL, Yuen KY. Clostridium difficile ribotype 027 arrives in Hong Kong. Int J Antimicrob Agents. 2009;34(5):492-3.

39. Cheng JW, Xiao M, Kudinha T, Xu ZP, Hou X, Sun LY, Zhang L, Fan X, Kong F, Xu YC. The first two Clostridium difficile Ribotype 027/ST1 isolates identified in Beijing, China-an emerging problem or a neglected threat? Sci Rep. 2016;6:18834

40. Surawicz CM, Brandt LJ, Binion DG, Ananthakrishnan AN, Curry SR, Gilligan PH, McFarland LV, Mellow M, Zuckerbraun BS. Guidelines for diagnosis, treatment, and prevention of Clostridium difficile infections. Am J Gastroenterol. 2013;108(4):478-98 quiz 499.

41. Gualtero SM, Abril LA, Camelo N, Sanchez SD, Davila FA, Arias G, Silva E, Bustos IG, Josa DF, Torres IC, et al. Characteristics of Clostridium difficile infection in a high complexity hospital and report of the circulation of the NAP1/027 hypervirulent strain in Colombia. Biomedica : revista del Instituto Nacional de Salud. 2017;37(4):466-72.

42. Slimings C, Riley TV. Antibiotics and hospital-acquired Clostridium difficile infection: update of systematic review and meta-analysis. J Antimicrob Chemother. 2014;69(4):881-91.

43. Clements AC, Magalhaes RJ, Tatem AJ, Paterson DL, Riley TV. Clostridium difficile PCR ribotype 027: assessing the risks of further worldwide spread. Lancet Infect Dis. 2010;10(6):395-404.

44. Pakyz AL, Jawahar R, Wang Q, Harpe SE. Medication risk factors associated with healthcare-associated Clostridium difficile infection: a multilevel model case-control study among 64 US academic medical centres. J Antimicrob Chemother. 2014:69(4):1127-31.

45. Vishwanath S, Singhal A, D'Souza A, Mukhopadhyay C, Varma M, Bairy I. Clostridium difficile infection at a tertiary care hospital in South India. J Assoc Physicians India. 2013;61(11):804-6.

46. Dubberke ER, Reske KA, Seiler S, Hink T, Kwon JH, Burnham CA. Risk factors for acquisition and loss of Clostridium difficile colonization in hospitalized patients. Antimicrob Agents Chemother. 2015:59(8):4533-43.

47. Bloomfield MG, Sherwin JC, Gkrania-Klotsas E. Risk factors for mortality in Clostridium difficile infection in the general hospital population: a systematic review. The Journal of hospital infection. 2012;82(1):1-12.

48. Furuya-Kanamori L, Stone JC, Clark J, McKenzie SJ, Yakob L, Paterson DL, Riley TV. SA, Clements AC: comorbidities, exposure to medications, and the risk of community-acquired Clostridium difficile infection: a systematic review and meta-analysis. Infect Control Hosp Epidemiol. 2015;36(2):132-41.

49. Yan Q, Zhang J, Chen C, Zhou H, Du P, Cui Z, Cen R, Liu L, Li W, Cao B, et al. Multilocus sequence typing (MLST) analysis of 104 Clostridium difficile strains isolated from China. Epidemiol Infect. 2013;141(1):195-9.

50. Clayton EM, Rea MC, Shanahan F, Quigley EM, Kiely B, Hill C, Ross RP. The vexed relationship between Clostridium difficile and inflammatory bowel disease: an assessment of carriage in an outpatient setting among patients in remission. Am J Gastroenterol. 2009;104(5):1162-9.

51. Huang $H$, Weintraub $A$, Fang $H$, Nord CE. Antimicrobial resistance in Clostridium difficile. Int J Antimicrob Agents. 2009;34(6):516-22.

52. Marston HD, Dixon DM, Knisely JM, Palmore TN, Fauci AS. Antimicrobial Resistance. Jama. 2016;316(11):1193-204.

53. Spigaglia P. Recent advances in the understanding of antibiotic resistance in Clostridium difficile infection. Therapeutic advances in infectious disease. 2016:3(1):23-42

54. Spigaglia P, Barbanti F, Mastrantonio P. European study group on Clostridium d: multidrug resistance in European Clostridium difficile clinical isolates. J Antimicrob Chemother. 2011;66(10):2227-34.

55. Putsathit $P$, Maneerattanaporn M, Piewngam $P$, Knight DR, Kiratisin P, Riley TV. Antimicrobial susceptibility of Clostridium difficile isolated in Thailand. Antimicrob Resist Infect Control. 2017;6:58.

56. King AM, Mackin KE, Lyras D. Emergence of toxin A-negative, toxin Bpositive Clostridium difficile strains: epidemiological and clinical considerations. Future Microbiol. 2015;10(1):1-4.

57. Tenover FC, Tickler IA, Persing DH. Antimicrobial-resistant strains of Clostridium difficile from North America. Antimicrob Agents Chemother. 2012;56(6):2929-32.

58. Chen YB, Gu SL, Shen P, Lv T, Fang YH, Tang LL, Li L. Molecular epidemiology and antimicrobial susceptibility of Clostridium difficile isolated 
from hospitals during a 4-year period in China. J Med Microbiol. 2018;67(1): 52-9.

59. Spigaglia P, Barbanti F, Louie T, Barbut F, Mastrantonio P. Molecular analysis of the gyr $A$ and gyr $B$ quinolone resistance-determining regions of

fluoroquinolone-resistant Clostridium difficile mutants selected in vitro Antimicrob Agents Chemother. 2009;53(6):2463-8.

60. Troeger C, Forouzanfar M, Rao PC, Khalil I, Brown A, Reiner RC, Fullman N, Thompson RL, Abajobir A, Ahmed M, et al. Estimates of global, regional, and national morbidity, mortality, and aetiologies of diarrhoeal diseases: a systematic analysis for the global burden of disease study 2015. Lancet Infect Dis. 2017;17(9):909-48.

61. Pires SM, Fischer-Walker CL, Lanata CF, Devleesschauwer B, Hall AJ, Kirk MD, Duarte AS, Black RE, Angulo FJ. Aetiology-specific estimates of the global and regional incidence and mortality of Diarrhoeal diseases commonly transmitted through food. PLoS One. 2015:10(12):e0142927.

62. Blixt T, Gradel KO, Homann C, Seidelin JB, Schonning K, Lester A, Houlind J, Stangerup M, Gottlieb M, Knudsen JD. Asymptomatic carriers contribute to nosocomial Clostridium difficile infection: a cohort study of 4508 patients. Gastroenterology. 2017;152(5):1031-41 e1032.

63. Truong C, Schroeder LF, Gaur R, Anikst VE, Komo I, Watters C, McCalley E, Kulik C, Pickham D, Lee NJ, et al. Clostridium difficile rates in asymptomatic and symptomatic hospitalized patients using nucleic acid testing. Diagn Microbiol Infect Dis. 2017;87(4):365-70.

Ready to submit your research? Choose BMC and benefit from:

- fast, convenient online submission

- thorough peer review by experienced researchers in your field

- rapid publication on acceptance

- support for research data, including large and complex data types

- gold Open Access which fosters wider collaboration and increased citations

- maximum visibility for your research: over $100 \mathrm{M}$ website views per year

At $\mathrm{BMC}$, research is always in progress.

Learn more biomedcentral.com/submissions 